\title{
Un estudio comparado de las políticas exteriores económicas: el caso de los países CIVETS*
}

\section{A Comparative Study of Foreign Economic Policies: The CIVETS Countries}

\author{
Angélica Guerra Barón **
}

Recibido: 11/o6/2013

Aprobado Evaluador Interno: 23/07/2013

Aprobado Evaluador Externo: 16/o8/2013

\section{Resumen}

Colombia, Indonesia, Vietnam, Egipto, Turquía y Sudáfrica guiaron sus políticas exteriores para cumplir con las medidas del Consenso de Washington e implementaron estrategias para atraer inversión extranjera a sus territorios como una forma de superar la crisis de deuda externa de los ochentas. Una vez las reglas comerciales multilaterales fueron acordadas en la Organización Mundial de Comercio (OMC), esos países alentaron sus políticas comerciales domésticas para ajustarse a esas reglas y a los estándares internacionales de inversión promovidos por el Banco Mundial. Luego de la creación del acrónimo CIVETS en 2009, como promisorias economías emergentes, los grupos económicos transnacionales focalizaron su atención en los "nuevos

\begin{abstract}
Colombia, Indonesia, Vietnam, Egypt, Turkey, and South Africa guided its foreign economic policies to comply with the Washington Consensus measures and implemented strategies to attract foreign investment to their territories as a possible way out from the external debt crisis of the eighties. Once multilateral trade rules were agreed under the World Trade Organization (WTO), those countries encouraged its domestic trade policies to cope with both the organization principles and international investment standards promoted by the World Bank. After the CIVETS acronym was created in 2009 as a group of promissory emergent economies, transnational economic groups focused its attention on the "new investment miracles", but none interest
\end{abstract}

doi:10.11144/Javeriana.PAPO19-1.ecpe

* Artículo de investigación. Este artículo presenta los resultados finales del proyecto de investigación "Las políticas de promoción de la inversión extranjera implementadas por los países CIVETS durante la primera década del S-XXI. Efectos sobre las relaciones internacionales", avalado por la Oficina de Fomento a la Investigación de la Pontificia Universidad Javeriana (Bogotá, Colombia).

${ }^{* *}$ Profesora, Pontificia Universidad Javeriana, Facultad de Ciencia Política y Relaciones Internacionales, Departamento de Relaciones Internacionales. Correo electrónico: angelica.guerra@ javeriana.edu.co 
milagros de inversión", pero ningún interés han has been shown by the CIVETS governments demostrado los gobiernos CIVETS por coordinar to coordinate its foreign economic policies in sus políticas exteriores económicas en asuntos de inversión. La administración colombiana investment issues. The current Colombian adactual se autoproclamó el liderazgo del grupo, mostrando la voluntad política de ir más allá, pero sin seguidores CIVETS sigue siendo un acrónimo. Argumento que los países CIVETS representan un caso de convergencia de las políticas exteriores económicas facilitado por razones sistémicas como la necesidad común de superar procesos históricos de transición económica y de ministration self-claimed the leadership of the group, showing the political will to go further, but without followers CIVETS keeps as an acronym. I argue that emergent economies recognized in CIVETS exemplify a case of foreign economic policies convergence facilitated by systemic reasons, such their common necessity to overcome historic processes of economic transition insertarse exitosamente al comercio global; así and insert successfully to the world trade; as como por variables domésticas como las ideas de well as domestic variables such the ideas of the los tomadores de decisión del grupo.

\section{Palabras clave:}

política exterior económica; CIVETS; convergencia; economías emergentes

\section{Keywords:}

foreign economic policies; CIVETS; convergence; emergent economies 


\section{Introducción}

En el sistema multipolar del siglo XXI los países en desarrollo (PED) han implementado estrategias para internacionalizar sus economías, las cuales van desde la adopción de principios multilateralmente consensuados a nivel global y sub-regional hasta políticas unilaterales para perfilarse mejor en los rankings internacionales. Enfocados fuertemente en criterios geoeconómicos, tales países intentan cumplir con las reglas de juego comerciales globales que a nivel multilateral son administradas por la Organización Mundial de Comercio (OMC), de manera que, como señalan Bütey Milner (2008, p. 745), los PED han aprovechado la membrecía a esa organización enfocando sus políticas exteriores en asuntos económicos.

Como resultado del eficiente aprovechamiento de las reglas comerciales globales, muchos PED son hoy considerados como economías emergentes ${ }^{1}$ interesadas en insertarse adecuadamente en las lógicas comerciales construidas en el marco del General Agreement on Trade and Tariffs (GATT, por sus siglas en inglés) de 1947. Desde entonces, como indica Salacuse (2010), muchos Estados se han venido involucrando en la negociación de acuerdos internacionales de inversión (AII) mediante los cuales los signatarios de tales tratados se comprometen a: (i) otorgar a los inversionistas y a las inversiones de su contraparte un particular tratamiento; $y$ (ii) activar un mecanismo de solución de controversias en caso de que alguna de las autoridades estatales consideren que el tratamiento acordado ha sido violado.

En ese contexto, muchas economías emergentes han entrado en la competencia por atraer inversión extranjera, principalmente directa (IED), ${ }^{2}$ para lo cual han encaminado sus políticas domésticas hacia el mejoramiento de las condiciones internas interesantes para grupos económicos transnacionales (empresas transnacionales: ETN), utilizando mecanismos de naturaleza tributaria (como la suscripción de acuerdos de doble tributación) y contractual (como los contratos de estabilidad jurídica) para avanzar en la competencia por atraer inversión extranjera. Por otro lado, las economías emergentes han desarrollado sus políticas exteriores económicas (PEE) focalizándose en la celebración de AII, tales como: los tratados de libre comercio (TLC); los acuerdos comerciales en el marco de los Acuerdos de Asociación con la Unión Europea (UE); y los Acuerdos para la

\footnotetext{
${ }^{1}$ Caracterizadas por su rápido crecimiento económico y por tener bajos niveles de ingreso (Hoskisson, Eden, Chung y Wright, 2000, p. 249), aunque también pueden tener ingresos medios con gran potencial de crecimiento (Meyer, 2004, p. 260).

${ }^{2}$ La definición de inversión extranjera varía en los distintos AII, pudiendo adoptar una visión amplia o muy restringida del término. En términos generales, podría considerarse inversión extranjera como "todo tipo de activo" incluyendo los derechos de propiedad sobre muebles e inmuebles; propiedad intelectual; acciones en la empresa adquirida por el inversionista extranjero; concesiones para la explotación de recursos naturales. La inversión extranjera directa (IED) es una categoría de inversión internacional en la cual el inversionista extranjero le interesa ser admitido y establecerse en otro territorio (host state) mediante la adquisición o control de una empresa con el fin de satisfacer un interés económico duradero (UNCTAD, 2004, p. 93, 97).
} 
Promoción y Protección Recíproca de Inversiones (APPRI o bilateral investment treaties: BIT). A partir de ello, se ha creado una compleja red de tratados internacionales en materia de inversión entre los actores del Sur y del Norte, lo que Salacuse (2010) denomina una compleja red de AII entre países exportadores de capital y aquellos que lo importan. Por otro lado, actores privados transnacionales han generado acrónimos distintos ${ }^{3}$ que reúnen países con características particulares de naturaleza principalmente económica.

En ese contexto, planteo que las economías emergentes agrupadas en el acrónimo CIVETS $^{4}$ ofrecen un ejemplo de convergencia de políticas exteriores en asuntos económicos facilitado por razones sistémicas como la necesidad común de superar históricos procesos de transición económica y de internacionalizar sus economías, así como por variables domésticas como las ideas de los tomadores de decisión del grupo. Para ello se analizarán las PEE adoptadas por los países CIVETS durante el período de tiempo comprendido entre los años 2000-2010 5 mediante un estudio comparado de tipo mixto desde la variable de las estrategias de negociación diseñadas para suscribir acuerdos internacionales de inversión, identificando los hitos histórico-económicos más relevantes.

Para la comprensión del argumento que se propone, se analizará la conducta estatal de los países CIVETS en lo que Cohen (1990) llama un esquema inside-out concentrándose, en principio, en las características internas de los mismos mediante la integración del nivel cognitivo pues la "cultura económica" legitima la toma de decisiones por las unidades geográficas (1990: 268); esto sin dejar de lado que "los Estados reaccionan a los estímulos que provienen del sistema internacional”, por lo cual se tendrán en cuenta asuntos "internacionales o estructurales" (Velosa, 2012, p. 40). Siguiendo a Velosa (2012), teniendo en cuenta que la conducta internacional de los Estados puede explicarse por el peso de las ideas de los tomadores de decisión, (p. 45), de igual forma también es válido tal planteamiento para el análisis de las PEE; esto que explica la integración de las dinámicas económicas globales las

\footnotetext{
${ }^{3}$ La Unidad de Investigación de BBVA señaló a los EAGLES (Emerging and Growth-Leading Economies) como un grupo de mercados emergentes que a diez años tendrían un crecimiento económico mayor del promedio de países industrializados. El Economic BRICs Research Institute (Japón) acuñó a los países VISTA (Vietnam, Indonesia, Sudáfrica, Turquía y Argentina) como economías emergentes con rápido crecimiento económico. The Economist creó el acrónimo MITSK para referirse a Brasil, Rusia, India, China, México y Corea del Sur como economías emergentes (Guerra-Barón, 2012b, p. 378). ${ }^{4}$ Creado por la Unidad de Inteligencia de The Economist (2009), el acrónimo CIVETS se refiere a la segunda ola de países que constituirían el milagro económico del futuro. Tomando en cuenta indicadores demográficos (población joven y creciente), económicos (diversidad y dinamismo) y políticos (relativa estabilidad política), esos países fueron considerados como interesantes destinos de IED (Guerra-Barón, 2012b, pp. 374, 375).

${ }^{5}$ El período de tiempo escogido se debe al viraje experimentado por los países CIVETS a partir del S. XXI, donde buena parte de ellos (Indonesia, Vietnam, Egipto, Turquía, Sudáfrica) intensificaron la estrategia negociadora de AII; mientras que Colombia optó por "insertarse" a la carrera de atracción de IED mediante la suscripción de APPRIs. principalmente.
} 
cuales también inciden en el proceso de toma de decisiones en política exterior, lo que Cohen (1990, p. 268) denomina un análisis outside-in. La integración de la vertiente sistémica y cognitiva es pertinente pues los hallazgos encontrados para el caso de los CIVETS dan muestra de que la formación de los tomadores de decisión tiene coherencia con el contexto histórico-económico dentro del cual cada Estado experimentó períodos de transición, así como la adopción de decisiones en materia de atracción de inversión extranjera.

Por incorporar en este análisis variables sistémicas de naturaleza económica se recurrirá al concepto de política exterior económica de Nel y Stephen (2010, p. 72), entendida como la construcción de decisiones y planes oficiales implementados por un Estado para interactuar en el ambiente económico internacional con el fin de satisfacer la demanda de desarrollo económico doméstico como es percibido por la clase o grupo dominante; la política exterior económica - que opera en el ámbito doméstico del Estado en relación con la economía global- incluye la política fiscal, monetaria, y comercial; así como estrategias de negociación y de atracción de inversión.

Este artículo se divide en cuatro secciones. En primer lugar, se esbozarán los principales planteamientos teóricos para el análisis propuesto. En una segunda sección se presentará el análisis comparado de los países CIVETS agrupados de la siguiente manera: (i) el caso de Colombia y Sudáfrica, por los "vasos comunicantes" que presentan (Guerra-Barón, 2012b, p. 378); (ii) Indonesia y Vietnam, por ser la porción representativa del Sudeste Asiático y por la historia compartida que tienen en ASEAN; y (iii) Egipto y Turquía, básicamente por su importancia geoestratégica y su calidad de pivotal states (Chase, Hill y Kennedy, 1996, p. 37) en sus regiones. Más adelante se discutirán los resultados encontrados, para, finalmente, abordar las conclusiones en la cuarta sección.

\section{La convergencia de políticas exteriores económicas y la influencia de las ideas}

Como resultado de la transnacionalización de los esquemas de corte neoliberal impulsados por el Fondo Monetario Internacional (FMI), el Banco Mundial (BM), y el Departamento del Tesoro de EE.UU., los países CIVETS, así como un gran número de PED, implementaron paquetes de estabilización y ajuste estructural conocidos como el Consenso de Washington. Este puede considerarse como un elemento bisagra de las tendencias de convergencia de las PEE de los PED, así como un elemento facilitador de la profundización de redes transnacionales de política en asuntos económicos y, en cierto modo, semilla de la compleja red de AII en la cual actores del Norte-Sur se ven envueltos. ${ }^{6}$

\footnotetext{
${ }^{6}$ La actual ola de globalización profundizada por la necesidad de ajustar las políticas domésticas a los esquemas multilaterales de post-IIGM en asuntos financieros y comerciales, principalmente, ha facilitado la convergencia de políticas nacionales sobre temas ambientales, de seguridad, laborales, e incluso tributarios.
} 
Entendiendo la convergencia como la tendencia a la similitud de las políticas nacionales, al punto de asemejarse a su estructura, procesos y desempeños (Drezner, 2001, p. 53), puede afirmarse que ese fenómeno se ejemplifica para el caso de las PEE de los CIVETS. De hecho, la convergencia se ha facilitado de cierta manera a partir de los noventas, no sólo como efecto derrame generado por las directrices del Consenso de Washington y por la creación de la OMC como organismo multilateral resultante de la Ronda Uruguay (1994) encargada de administrar las dinámicas del comercio global ${ }^{7}$ sino por la necesidad de los países CIVETS de internacionalizar sus economías y posicionarse en las nuevas lógicas del sistema económico internacional. De igual forma, tales países diseñaron políticas domésticas para convertirse en países receptores (host countries) de inversión extranjera propiciando un clima de inversión ${ }^{8}$ ideal para potenciales ETN. Sin embargo, la convergencia de PEE de los CIVETS no ha sido resultado de esfuerzos gubernamentales por coordinar sus políticas, sino que aquel fenómeno es el resultado de las propias dinámicas de país encaminadas a la satisfacción de sus objetivos nacionales de corte económico.

Así, es válido cuestionarse si además de los factores económicos, demográficos, políticos y de inversión que enmarcaron la creación del acrónimo CIVETS en 2009, existen esfuerzos gubernamentales por trascender de la mera convergencia de PEE hacia la coordinación en asuntos puntuales de inversión. De forma más puntual, ¿̇es válido pensar que, tras la creación del acrónimo, el autoproclamado liderazgo del gobierno colombiano pueda traducirse en la disposición de los otros países de aceptar su posición en el grupo y gestar luego puntos comunes de encuentro en temas compartidos de interés estratégico? En uno u otro caso, el abordaje teórico para analizar la PEE de los CIVETS se entiende mejor a través de las teorías de convergencia de políticas donde el elemento central son los elementos económicos, así como las ideas y el contexto dentro del cual los principales tomadores de decisión de los países las conciben. ${ }^{9}$

\footnotetext{
${ }^{7}$ En asuntos arancelarios (GATT), de servicios (General Agreement on Trade and Services: GATS, por sus siglas en inglés) y de propiedad intelectual (Trade Related Issues on Property Rights: TRIPS, por sus siglas en inglés).

${ }^{8}$ Entendido como un conjunto de medidas diseñadas por los países receptores de la inversión extranjera (host countries) por influenciar las decisiones de inversión y cuyo objetivo es la atracción de los inversionistas (UNCTAD, 2004). El clima de inversión resulta de distintos factores que son atendidos por los inversionistas como: restricciones a foráneos sobre la propiedad; promoción a la inversión; aprobación de procedimientos; requisitos de desempeño; acceso a la tierra; empleo y expatriación de personal; restricciones a los miembros del consejo, convertibilidad de moneda; protección contra la expropiación; protección a la propiedad intelectual; provisión de principios de trato nacional; acceso a arbitraje internacional de comercio e inversión (IFC, 2010).

${ }^{9}$ Sin ser este particularmente el objetivo de la discusión. Tan solo se acepta que la actual ola de globalización ha facilitado la convergencia de PEE, particularmente cuando las variables que se analizan son de corte financiero y comercial en materia de inversión, puntualmente.
} 
La convergencia de políticas es explicada por los estudiosos como resultado de un análisis estructural, donde las condiciones - añado económicas- afectan las unidades políticas; así, los Estados están sujetos a presiones externas que determinan su conducta y circunscriben sus actuaciones (Drezner, 2001, p. 57) al punto de poder anticipar su contenido. Por ello, las políticas domésticas diseñadas por los actores estatales para interactuar en el contexto económico global obedecen a varios factores, como: (i) los consensos multilateralmente alcanzados; (ii) la adopción de patrones de conducta por aquellos que no hacen parte de tales consensos (Goldstein, Rivers y Tomz, 2007, p. 38); (iii) la imitación de casos exitosos de países cercanos, ${ }^{10}$ y (iv) la presión directa o indirecta de grupos económicos sobre las autoridades nacionales.

Ante la multi-causalidad anunciada, hay varios enfoques teóricos que permiten explicar la convergencia de políticas, distinguiendo concepciones basadas en la estructura, así como enfoques basados en el agente. Mientras que la primera concepción se refiere a la convergencia de políticas como resultado de la homogenización de diferentes políticas nacionales en una política global, las teorías basadas en el agente utilizan el término coordinación. Los conceptos utilizados por cada enfoque teórico (convergencia/ coordinación) no son el único elemento diferenciador, pues también ofrecen concepciones opuestas sobre la causa que genera la convergencia. Bajo una lógica estructural, la convergencia de políticas se atribuye a fenómenos económicos que ejercen presión al punto que los Estados siguen la corriente ya fijada para no perder competitividad, mientras que los enfoques basados en el agente consideran que la causa de la presión proviene de las ideas, las cuales, al mismo tiempo, han sido comúnmente aceptadas en organizaciones internacionales (Drezner, 2001, p. 57).

Si bien para el análisis comparado de las PEE de los países CIVETS se recurrirá a la lógica estructural enriquecida por el enfoque basado en el agente, no se acogerá el uso del término coordinación propio de este último enfoque sino que se partirá por aceptar que ese grupo de economías emergentes, por el mismo proceso de generación del acrónimo, no han optado por coordinar sus PEE. Por el contrario, las estrategias unilaterales y bilaterales adoptadas por tales países son resultado en buena parte de las dinámicas domésticas y su relación con el contexto económico global, al punto de que las políticas de los países CIVETS, principalmente en asuntos de inversión extranjera, convergen casi como un patrón de conducta. Esos países no han gestionado acuerdos comunes "on the aceptable bounds of regulatory policies" (Drezner, 2001, p. 57). De hecho, la creación del término CIVETS no resulta de la necesidad de los gobiernos de lograr acercamientos con el fin de coordinar sus PEE sino que por el contrario, el término surge en 2009

\footnotetext{
${ }^{10}$ Como sería el caso de Chile en el contexto suramericano y la receptividad de Colombia por el buen desempeño de aquél (Simmons y Zachary, 2004, p. 175).
} 
como resultado del análisis de un actor no gubernamental (Unidad de Inteligencia, The Economist) con alto nivel de influencia sobre otros actores estatales y no estatales.

Tras la aclaración conceptual planteada, para el análisis de la convergencia de políticas de los países CIVETS, se acogerán algunos elementos del Institucionalismo Neoliberal, omitiendo otros enfoques. ${ }^{11}$ Según este enfoque, los factores estructurales de corte económico no sólo ayudan a explicar el grupo sino que permiten validar el hecho de que los Estados aún tienen algún nivel de injerencia en las políticas que diseñan; toda vez que las regulaciones nacionales responden a compromisos internacionalmente asumidos (OMC, FMI) que presionan a los Estados a seguir ciertas rutas, generando un nivel de "predicción" de las PEE de economías emergentes..$^{12}$ Los seguidores del Institucionalismo Neoliberal consideran que las unidades geográficas coordinan sus políticas; sin embargo, como se planteó arriba, para el análisis comparado que se propone de las PEE de los países CIVETS se adoptará el término de convergencia, pues el acrónimo no surge como resultado de tal coordinación estatal donde sus representantes han desarrollado espacios de construcción común para lidiar con asuntos también comunes mediante la cooperación sino que el grupo resulta de la identificación de elementos comunes en asuntos políticos, demográficos y, principalmente, económicos..$^{13}$

Hipotéticamente, el uso del término coordinación de las PEE de los CIVETS podría aplicarse si el grupo adoptara una posición de bloque en organizaciones internacionales (OMC, FMI, MIGA, CIADI), ${ }^{14}$ lo que claramente implicaría la transición de un acrónimo a la generación de un bloque de coordinación. Sin embargo, al tratarse CIVETS meramente de un acrónimo donde los países no han procurado la creación de ningún proceso de integración (Guerra-Barón, 2012b, p. 374), el término de coordinación no se utilizará para su explicación.

Para el análisis debe tenerse en cuenta un elemento común de las seis economías como lo es la decisión de adoptar postulados de corte neoliberal - traducidos en la apertura económica- profundizados por las lógicas del comercio mundial fijadas en

\footnotetext{
${ }^{11}$ Como aquellos meramente estructurales que basan la explicación al fenómeno de convergencia de políticas en la movilidad del capital como razón principal para explicar las motivaciones y estrategias desarrolladas por un Estado (Race to the bottom hypothesis), lo que implicaría obviar la trascendencia de las ideas y las instituciones en la construcción de la política exterior de los países en temas económicos (Drezner, 2001).

${ }^{12}$ De hecho, no acoger las obligaciones que los Estados han asumido en las organizaciones internacionales mencionadas $y$, eventualmente, denunciar el cumplimiento de los tratados constitutivos; significaría desalinearse a las expectativas ya generadas $y$, probablemente, correr el riesgo de quedarse rezagado de las lógicas que en materia comercial se siguen globalmente.

${ }^{13}$ Población joven y creciente; economía diversa y dinámica; relativa estabilidad política; y, por ende, interesantes destinos de IED (Guerra-Barón, 2012b, p. 375).

${ }^{14}$ Teniendo en cuenta que ni Vietnam ni Sudáfrica son miembros plenos de CIADI (2013).
} 
la Ronda Uruguay (1994) y por la necesidad de tener un buen desempeño como países receptores (host countries) de inversión extranjera. ${ }^{15}$ Sin embargo, esas variables económicas externas no han sido la única causa que ha generado la convergencia de las estrategias de esos países. Adicionalmente, el rol de los tomadores de decisión y las ideas que los han inspirado a generar los cambios siguen siendo determinantes en la medida que su background ha influido en la decisión de implementar ajustes domésticos en los Estados para responder a las inquietudes de los grupos económicos dominantes; mostrando que aquellos aún tienen el poder de determinar hacia dónde direccionar su relación con el mercado, es decir, aún tienen la potestad de decidir de qué forma sobrevivirán en el contexto económico global. ${ }^{16}$ Así que, en el análisis que se propone se busca incorporar el "eslabón perdido" del que habla Ravenhill (2010, p. 551) en el marco de la Economía Política Internacional (EPI), ${ }^{17}$ esto es: ¿̇cuándo y de qué manera las ideas y las normas importan en el análisis de los fenómenos económicos?

\section{Los CIVETS: un caso de convergencia de políticas}

Tras la creación de varias siglas, ${ }^{18}$ la Unidad de Inteligencia de The Economist (2009) utilizó el acrónimo CIVETS $^{19}$ para referirse a la segunda ola de países que constituirían el milagro económico del futuro. Tomando en cuenta indicadores demográficos (población joven y creciente), económicos (economía diversa y dinámica) y políticos (relativa estabilidad política), tales países han sido catalogados como interesantes destinos de IED (Guerra-Barón, 2012b, p. 374).

\footnotetext{
${ }^{15}$ Sumado a ello, Katzenstein (1977, p. 595) señala que durante los noventas especialmente el giro gradual de problemáticas de seguridad hacia temas económicos ha aumentado peso relativo de las estructuras domésticas en la política exterior económica.

${ }^{16}$ Un buen ejemplo lo ofrece la PEE brasileña a partir de Lula Da Silva pues "la negociación de TLC, como expresión del unilateralismo, no es parte de la política exterior económica brasileña, por el contrario, la balanza de prioridades se inclina claramente hacia la multilateralidad y la integración en la región" (Guerra-Barón, 2012a, p.405).

${ }^{17}$ Concibiendo la EPI como un campo de estudio que incluye "all work for which international economic factors are an important cause or consequence. This ranges from the domestic politics of trade and exchange rate policy, through the politics of World Trade Organization (WTO) dispute settlements, to the impact of international flows of goods or capital on national political systems" (Frieden y Martin, 2002, p. 118).

${ }^{18}$ En 2000, Jim O'Neill (Goldman Sachs) acuñó el grupo de economías emergentes del futuro: BRIC (Brasil, Rusia, India y China). Años más tarde, se crearon los BRICSAM (BRIC más Sudáfrica y México). Algunos han incluido otros países al referirse a los BRICSAM: BRIC, más Sudáfrica (Guerra-Barón, 2012b, p. 374).

${ }^{19}$ Ampliamente difundido por Michael Geogheghan EN 2010, para referirse a las "nuevas BRICs" (Guerra-Barón, 2012b, p. 345).
} 
En términos demográficos, los CIVETS cuentan con una población significativa (603.973.735, CIA World Factbook) y joven, ${ }^{20}$ siendo Indonesia el país con la población más representativa ${ }^{21}$ y Egipto que ostenta la más alta tasa de crecimiento anual de la población $(1,88 \%)^{22}$, lo que claramente confirma el elemento demográfico del acrónimo. Los seis son países de ingresos medios, donde Colombia, Turquía y Sudáfrica (mediosaltos) superan a Indonesia, Vietnam y Egipto por ser países de ingresos medios-bajos (Guerra-Barón, 2012b, p. 375).

En términos de la jerarquía regional del poder, Indonesia, Turquía, Egipto y Sudáfrica $^{23}$ son considerados como "pivotal states" ${ }^{24}$ y potencias regionales (Shim y Flamm, 2012, p. 11; Nolte, 2010, p. 882), mientras que Colombia es una potencia secundaria en Suramérica, ${ }^{25}$ luego de Brasil (Flemes, 2012). Vietnam, que actualmente busca fortalecer las relaciones con Japón, fue recientemente reconocido como un jugador de peso en el Sudeste Asiático. ${ }^{26}$

\section{Colombia y Sudáfrica: más convergencias que divergencias}

La experiencia de Colombia y Sudáfrica puede catalogarse como complementaria, no sólo por haber experimentado situaciones de conflicto y violencia (Murillo, 2012, p. 425), sino por haber acogido procesos de liberalización de sus economías en los noventa y de haber adoptado principios constitucionales comunes en épocas similares ${ }^{27}$ (ver Tabla 1). Ambos países atraviesan por un proceso de consolidación nacional aún

\footnotetext{
${ }^{20}$ Considerando a la población joven entre edades de 15 a 64 años, para 2012 el $71 \%$ de la población vietnamita es joven, seguido de Turquía (67\%), Indonesia (66\%), Colombia (66\%), Sudáfrica (65\%), y Egipto (63\%). World Bank Data.

${ }^{21}$ La población indonesia estimada a $07 / 2013$ es de 251,160,124, seguido de Vietnam $(92,477,857)$ y Egipto $(85,294,388)$. (CIA World Factbook).

22 Luego Turquía (1.16\%) y Vietnam (1,03\%). (CIA World Factbook).

${ }^{23}$ Aunque Sudáfrica es considerada como una potencia media por Alden y Vieira (2007, p. 139).

${ }^{24}$ Considerados como Estados pivotes por tener una población significativa y una localización geográfica importante, sin dejar de lado un elemento central: la capacidad de afectar la estabilidad regional e internacional al punto que su colapso podría traer efectos en términos migratorios; violencia comunal; polución; enfermedades, entre otros (Chase, Hill y Kennedy, 1996, p. 37).

${ }^{25}$ Junto con Argentina, Chile, Venezuela. Considerando las potencias secundarias como los Estados que ocupan la segunda posición más poderosa dentro de una jerarquía regional. La posición secundaria está determinada por sus relativas capacidades en términos materiales y/o de ideas (Cooper et al y Flemes y Wojczewski, citados por Flemes, 2012, p. 21).

${ }^{26}$ Así lo expresó el Vicepresidente de la India Mohammad Hamid Ansari el 15/01/2013: "Vietnam has emerged as a regional power in South-East Asia with political stability and a dynamic economy". Disponible en: http://www.dnaindia.com/world/1789118/report-vietnam-has -emerged-as-a-regional-power-in-south-east-asia-hamid-ansari

${ }^{27}$ Colombia, 1991; Sudáfrica, 1994.
} 
Tabla 1

Cuadro comparativo - PEE de los países CIVETS (2000-2010)

\begin{tabular}{|c|c|c|c|c|c|c|}
\hline \multirow[b]{2}{*}{ País } & \multicolumn{2}{|c|}{ Formulación de la PEE } & \multicolumn{2}{|c|}{ Negociación de AII } & \multirow{2}{*}{$\begin{array}{c}\text { Estándares } \\
\text { de protección } \\
\text { reconocidos en AII }\end{array}$} & \multirow{2}{*}{\begin{tabular}{|c|} 
Socios \\
comerciales \\
comunes \\
\end{tabular}} \\
\hline & $\begin{array}{c}\text { Características } \\
\text { generales }\end{array}$ & $\begin{array}{c}\text { Roles de entidades } \\
\text { públicas }\end{array}$ & $\begin{array}{l}\text { Total } \\
\text { AII* }\end{array}$ & \begin{tabular}{|c|} 
APPRIs \\
suscritos
\end{tabular} & & \\
\hline $\begin{array}{l}\frac{0}{0} \\
\text { है } \\
\text { 응 }\end{array}$ & $\begin{array}{l}\text { PEE desintegrada y } \\
\text { presidencialista. }\end{array}$ & $\begin{array}{l}\text { Líder: Ministerio de Comercio, } \\
\text { Industria y Turismo: MCIT } \\
\text { (por mandato legal). } \\
\text { Promoción de comercio e } \\
\text { inversión depende del MCIT } \\
\text { (Proexport). } \\
\text { Apoyo: ministerios y } \\
\text { departamentos, según } \\
\text { temática a abordar. } \\
\end{array}$ & 47 & $\begin{array}{l}6 \\
(100 \% \\
\text { suscritos en } \\
\text { SXXI) }\end{array}$ & $\begin{array}{l}\text { Principios } \\
\text { consensuados } \\
\text { en GATT/OMC y } \\
\text { los derivados del } \\
\text { derecho internacional } \\
\text { consuetudinario. }\end{array}$ & \\
\hline $\begin{array}{l}\frac{\pi}{w} \\
\stackrel{0}{5} \\
\frac{0}{0}\end{array}$ & $\begin{array}{l}\text { PEE: constituida a } \\
\text { partir de la crisis de } \\
\text { 1997. Aspira a ser } \\
\text { estatal. }\end{array}$ & $\begin{array}{l}\text { Líder: Ministerio de Comercio. } \\
\text { Principal agencia estatal } \\
\text { responsable de coordinar } \\
\text { la política comercial y las } \\
\text { relaciones comerciales } \\
\text { internacionales (incluyendo } \\
\text { asuntos OMC). }\end{array}$ & 77 & $\begin{array}{l}62 \\
\text { (42\% suscritos } \\
\text { en la década } \\
\text { de los } \\
\text { noventa) }\end{array}$ & $\begin{array}{l}\text { Principios } \\
\text { consensuados } \\
\text { en GATT/OMC y } \\
\text { los derivados del } \\
\text { derecho internacional } \\
\text { consuetudinario. }\end{array}$ & \\
\hline 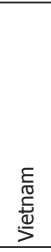 & $\begin{array}{l}\text { Política exterior } \\
\text { presidencialista. } \\
\text { Teóricamente, en } \\
\text { búsqueda de la } \\
\text { independencia y } \\
\text { autosuficiencia en pro } \\
\text { de la diversificación y } \\
\text { "multilateralización" } \\
\text { de las relaciones } \\
\text { internacionales. } \\
\end{array}$ & $\begin{array}{l}\text { PEE: Enfocada hacia la } \\
\text { integración económica en } \\
\text { ASEAN; la suscripción de TLC; } \\
\text { y asuntos multilaterales ante } \\
\text { la OMC. } \\
\text { Líder: Ministerio de Industria } \\
\text { y Comercio. }\end{array}$ & 73 & $\begin{array}{l}58 \\
\text { (35\% suscritos } \\
\text { en la década } \\
\text { de los } \\
\text { noventa) }\end{array}$ & $\begin{array}{l}\text { Principios } \\
\text { consensuados } \\
\text { en GATT/OMC y } \\
\text { los derivados del } \\
\text { derecho internacional } \\
\text { consuetudinario. }\end{array}$ & \begin{tabular}{|l|} 
China \\
India \\
Japón \\
España \\
Reino Unido \\
Suiza
\end{tabular} \\
\hline 夢 & $\begin{array}{l}\text { La política exterior } \\
\text { egipcia sirve para } \\
\text { la consecución } \\
\text { de los objetivos, } \\
\text { principalmente en las } \\
\text { áreas relacionadas } \\
\text { con las funciones } \\
\text { diplomáticas. }\end{array}$ & $\begin{array}{l}\text { La política comercial es } \\
\text { implementada por el Ministro } \\
\text { de Comercio Exterior e } \\
\text { Industria creado en 2004, } \\
\text { resultado de la fusión del } \\
\text { Ministro de Comercio Exterior } \\
\text { y el Ministro de Industria y } \\
\text { Desarrollo Tecnológico. } \\
\text { Líder: Ministro de Comercio } \\
\text { Exterior e Industria. } \\
\end{array}$ & 150 & $\begin{array}{l}100 \\
\text { (71\% suscritos } \\
\text { en la década } \\
\text { de los } \\
\text { noventa) }\end{array}$ & $\begin{array}{l}\text { Principios } \\
\text { consensuados } \\
\text { en GATT/OMC y } \\
\text { los derivados del } \\
\text { derecho internacional } \\
\text { consuetudinario. }\end{array}$ & \\
\hline 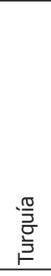 & \begin{tabular}{|l|} 
La política exterior \\
turca en términos \\
económicos se ha \\
replanteado para \\
superar la crisis \\
económica (estructural) \\
y ajustarse a los \\
estándares europeos. \\
Fuerte influencia de la \\
comunidad de negocios \\
en la formulación. \\
\end{tabular} & $\begin{array}{l}\text { El Ministerio de Economía de } \\
\text { Turquía determina las políticas } \\
\text { relacionadas con comercio } \\
\text { exterior de bienes y servicios; } \\
\text { también lidera las relaciones } \\
\text { bilaterales, regionales y } \\
\text { multilaterales en asuntos } \\
\text { económicos y aquellas } \\
\text { relacionadas con la atracción } \\
\text { de la IE al país. } \\
\text { Líder: Ministerio de Economía. }\end{array}$ & 111 & $\begin{array}{l}56 \\
(56 \% \\
\text { suscritos en la } \\
\text { década de los } \\
\text { noventa) }\end{array}$ & $\begin{array}{l}\text { Principios } \\
\text { consensuados } \\
\text { en GATT/OMC y } \\
\text { los derivados del } \\
\text { derecho internacional } \\
\text { consuetudinario. }\end{array}$ & \\
\hline 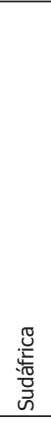 & $\begin{array}{l}\text { La política exterior } \\
\text { sudafricana se } \\
\text { proclama como } \\
\text { "próspera, pacífica, } \\
\text { democrática, no } \\
\text { basada en la raza, no } \\
\text { sexista y unida". }\end{array}$ & $\begin{array}{l}\text { El Departamento de } \\
\text { Comercio e Industria dirige } \\
\text { la participación de Sudáfrica } \\
\text { en la economía global y el } \\
\text { ambiente comercial mediante } \\
\text { la celebración de acuerdos } \\
\text { con socios comerciales y } \\
\text { mercados emergentes. } \\
\text { Junto con las agencias de } \\
\text { promoción a la inversión } \\
\text { promueve la celebración de } \\
\text { acuerdos de cooperación con } \\
\text { mercados alineados con las } \\
\text { relaciones internacionales de } \\
\text { Sudáfrica. } \\
\text { Líder: Departamento de } \\
\text { Comercio e Industria. }\end{array}$ & 91 & $\begin{array}{l}46 \\
(59 \% \\
\text { suscritos en la } \\
\text { década de los } \\
\text { noventa) }\end{array}$ & $\begin{array}{l}\text { Principios } \\
\text { consensuados } \\
\text { en GATT/OMC y } \\
\text { los derivados del } \\
\text { derecho internacional } \\
\text { consuetudinario. }\end{array}$ & \\
\hline
\end{tabular}

* Acuerdos suscritos, incluyendo TLC y APPRI.

**Nación Más Favorecida; Trato Nacional; Expropiación previa compensación; solución de controversias.

Elaboración propia, con base en las páginas oficiales de los ministerios de los países; UNCTAD Database; WTO-RTA Database. 
no resuelto donde las divisiones internas son profundas y la deuda social (pobreza e inequidad) siguen sin respuesta. ${ }^{28}$

Para Colombia, los años noventa marcaron el fin de la histórica precariedad en su intento por insertarse a la economía global. ${ }^{29}$ La apertura económica abanderada por el presidente Gaviria (1990-1994) y apoyada por su sucesor Ernesto Samper (1994-1998), la posterior promoción de la IED como eje de la internacionalización, y la creación de una estrategia a desarrollar promulgada por el presidente Pastrana (1998-2002), llevaron a la necesidad de brindar seguridad jurídica a los inversionistas extranjeros; lo que se tradujo en una enmienda constitucional coherente con los compromisos alcanzados multilateralmente en la OMC. ${ }^{30}$

A inicios del siglo XXI, el entrante presidente Uribe (2002-2006), ${ }^{31}$ con una postura de "centro-derecha" que se reflejó en el manejo doméstico y en la forma como condujo las relaciones exteriores de Colombia (Pastrana y Vera, 2012, p. 64), consolidó la confianza inversionista, entre otros pilares, como uno de los temas cruciales de su administración. Tras la reelección de Uribe, su segunda administración (2006-2010) se centró en promover la entrada de inversión extranjera como política para lograr un crecimiento económico sostenido. Con el fin de alcanzar el desarrollo empresarial y tecnológico así como la innovación, la inserción internacional y la facilitación del comercio, se gestó la suscripción de contratos de estabilidad jurídica entre los inversionistas extranjeros y el gobierno (2005), esperando que Colombia se consolidara como una oportunidad de negocio y se desligara del tradicional problema del narcotráfico. Como ejemplo de la política exterior "presidencialista y personalista" de Colombia (Tickner, 2007, p. 97), Uribe promovió la creación de una agenda de acuerdos comerciales con socios relevantes para el país.

Así pues, Colombia experimentó una transición tardía del auto enclavamiento comercial, del limitado aprovechamiento en el régimen comunitario andino, de la solicitud de renovación de preferencias arancelarias a EE.UU. y la UE, y de un tratado con México en 1995 (G3, ahora G2) a una actitud activa proclive a negociar con socios políticos y económicos considerados como estratégicos. Sin embargo, en la apuesta por internacionalizarse adecuadamente, algunos sectores económicos (lácteo, agrícola,

\footnotetext{
${ }^{28}$ En ese sentido ver Allen (2006, p. 5).

${ }^{29}$ Misión de Política Exterior de Colombia (2010). Disponible en: http://web.presidencia.gov.co/ sp/2010/abril/16/mision_politica_exterior.pdf

${ }^{30}$ De esa manera, el texto fue enmendado en 1999 para eliminar la facultad que tenía el Gobierno de llevar a cabo expropiaciones sin indemnización "por razones de equidad". Adicionalmente, al igual que muchos PED, las reformas profundas (apertura y liberalización económica) impulsadas por la crisis del Sistema de Bretton Woods, llevó a que muchas economías relajaran los controles sobre los flujos de capital durante los ochenta y noventa (Mukherjee y Singer, 2010, p. 46).

${ }^{31}$ Abogado y politólogo con estudios de Administración y Gerencia y Negociación de Conflictos de la Escuela de Extensión de la Universidad de Harvard.
} 
autopartes, farmacéutico) alegaron inconformidades y ejercieron presión para acotar la negociación de otra forma (Guerra-Barón, 2012b, p. 377).

Tras casi una década de la "pequeña política o microgerencia" de Uribe (Pastrana y Vera, 2012, p. 58), el presidente Santos ${ }^{32}$ hereda la agenda negociadora de su antecesor ${ }^{33}$ y acentúa su interés de gobierno en profundizar la política exterior económica. Aprovechando el "estilo gerencial [...] en la conducción de las relaciones internacionales" con "alta capacidad de delegación de la función político-diplomática en la Cancillería" (Pastrana y Vera, 2012, p. 58), el lobby del gobierno santista logró que el Congreso estadounidense diera luz verde al TLC con Colombia, mientras que el acuerdo con la Asociación Europea de Libre Comercio (EFTA, por sus siglas en inglés) entró provisionalmente en vigencia. ${ }^{34}$ Santos ha reflejado la adopción de un marcado acento económico en la PEE en esta época mediante la consolidación de sinergias pragmáticas concretadas en el Área de Integración Profunda (AIP) con Chile, Perú y México (2011); la entrada en vigencia del Acuerdo de Asociación con la UE; y la inclusión de nuevos países para la negociación de TLC: Vietnam, Egipto y Turquía - como las cuotas de CIVETS-, Corea del Sur, China, Israel, Panamá, Singapur, y Japón (Guerra-Barón, 2012a, p. 395).

De manera similar al caso colombiano -en términos cronológicos- Sudáfrica se vio en la necesidad de integrarse en el contexto mundial en los noventas tras haber sido considerado durante el apartheid como un Estado paria con una política de "asilamiento diplomático" por la comunidad internacional (Geldenhuys, 1984, citado por Flemes, 2007, p. 18). Tras el apartheid se realizaron en ese país las primeras elecciones democráticas multirraciales (1994), se dio la llegada al poder del Congreso Nacional Africano (CNA) y con éste el viraje de la política económica hacia el desarrollo de ideas neoliberales como el libre comercio, la apertura de mercados y la atracción de IED como mecanismo de crecimiento económico (Alden y Vieira, 2007, p. 146). Bajo la presidencia de Mandela (1994-1999) se activó el Programa para la Reconstrucción y el Desarrollo basado en el crecimiento económico para lograr equidad social, y se adoptó una estra-

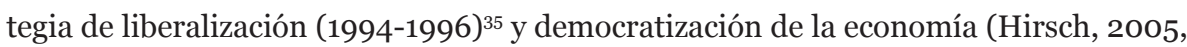

\footnotetext{
${ }^{32}$ Economista y administrador de empresas, con posgrados en la Escuela de Economía de Londres, de la Universidad de Harvard y la Escuela Fletcher de Leyes y Diplomacia (Guerra-Barón, 2012a, p. 394). ${ }^{33}$ Esto es, TLC con Canadá, Corea del Sur, Chile, Panamá y Triángulo Norte (El Salvador, Guatemala y Honduras, TLC); APPRI con China, India, Japón y Perú, Reino Unido (Guerra-Barón, 2012a, p. 395). ${ }^{34}$ Asociación Europea de Libre Comercio conformada por Islandia, Liechtenstein, Noruega y Suiza. EI TLC negociado entre los países EFTA y Colombia entrará en vigencia para Colombia, Liechtenstein y Suiza el 1/07/2011. Organization of American States (OAS).

${ }^{35}$ Durante los noventa, en medio de cambios políticos profundos, se optó también por ajustar su política macroeconómica e industrial (Hayter, Reinecke y Torres, 2001, p. 11, 12) con medidas como las políticas para desarrollar industrias de capital intensivo (zonas de desarrollo industrial en las regiones más afectadas por el apartheid), procurando el acceso equitativo a los activos
} 
p. 210). Al igual que en Colombia, esto significó un reto enorme para un país asilado económicamente (Hayter, Reinecke y Torres, 2001, p. 5) ${ }^{36}$. En ese contexto, el "renacimiento sudafricano" ${ }^{37}$ se evidenció en su política exterior con el liderazgo del país en la creación de la Comunidad de Desarrollo de África Meridional (SADC, por sus siglas en inglés) en 1992 y su aceptación como miembro pleno de la OMC tres años más tarde.

En medio de las intensas transformaciones experimentadas por los sudafricanos, además de las "relaciones singularmente complejas" (Alden y Vieira, 2007, p. 141) de ese país en su región debido principalmente a su preponderante posición económica y militar, la apuesta ha sido por impulsar el multilateralismo y el liderazgo en la conformación de bloques económicos como la SADC. En ese contexto, el presidente Mbeki (1999-2009) recibió la nueva Sudáfrica (Guy, 2000, p. 59) con la necesidad de insertarse internacionalmente, superar su tradicional asilamiento internacional y procurar que la población se beneficiara de las transiciones sin una base discriminatoria por razón de raza o género; todo ello en la promoción de la nueva posición de Sudáfrica como líder “natural” del continente africano. Bajo el liderazgo mbekiano, Sudáfrica adoptó la "estrategia mariposa” para profundizar las relaciones económico-comerciales con países de la región, donde África sería el cuerpo y otros países (como Brasil e India) serían las alas (Alden y Vieira, 2007, p. 148).

Aunque algunos consideran la política exterior bajo Mbeki como ambigua -rezago en parte del manejo dado por Mandela (Bischoff 2003, citado por Nathan, 2005)-y fuertemente presidencialista (Vale y Maseko, 1998, p. 285), otros la califican como totalmente coherente (Nathan, 2005) y pragmática (Landsberg, 2010a, 2010b). En uno u otro caso, es evidente que el presidente sudafricano, en consonancia su background ${ }^{38}$ le apostó a la necesidad de transformar la economía del tercer mundo y de que la población tradicionalmente marginalizada de los beneficios lograra algún provecho. Por ello, Mbeki intentó profundizar la integración regional, a lo que Hirsch (2005, pp. 233, 245) llama la "segunda economía".

Así, Sudáfrica se consolidó como miembro de SACU (Unión Aduanera de África del Sur, 2002) y ganador en el bloque (Hayter, Reinecke y Torres 2001, pp. 69-76), al tiempo

productivos y a la tierra -intentando dejar atrás la propiedad concentrada en los blancos-, y brindando protección real a los trabajadores más vulnerables. Paralelamente, se desarrolló una política de acceso a la educación de calidad y desarrollo de habilidades.

${ }^{36}$ Sin embargo, el contexto histórico sudafricano plantea retos más ambiciosos en términos del aprovechamiento de los efectos de su integración en las reglas y dinámicas del mercado, aún cuando ello implique ir contra mandatos electorales en temas como la redistribución del ingreso y beneficios sociales (Allen, 2006, pp. 3, 128).

${ }^{37}$ En cinco grandes áreas: intercambio cultural; emancipación de las mujeres africanas del patriarcado; movilización de la juventud; ampliación, profundización y mantenimiento de la democracia; e inicio del desarrollo económico sostenible (Vale y Maseko, 1998, p. 274).

${ }^{38}$ Master en economía de la Universidad de Sussex, Reino Unido. 
que se benefició de una zona de libre comercio (SADC, 2002) y se consolidó un acuerdo con EFTA (2006). ${ }^{39} \mathrm{Si}$ bien la iniciativa mbekiana de fortalecer las relaciones comerciales de Sudáfrica con ciertos interlocutores regionales y extra-regionales, según Draper (2011), la posición del país a partir de su reconocimiento como "un miembro privilegiado de varios clubes de gobernanza global [debido a] su relativo peso económico en África sub-Sahariana y su legado de 'poder suave' derivado de la transición pacífica del apartheid a la democracia” (pp. 207, 209, 212) está en jaque, particularmente por el manejo de las políticas estatales orientadas al fortalecimiento de ciertos sectores estratégicos. ${ }^{40}$

Tras la renuncia de Mbeki y una corta presidencia interina, ${ }^{41}$ el ganador de las elecciones, Jacob Zuma (2009-actualidad), ha adelantado una política exterior similar a la de su antecesor. Si bien la política exterior de Mandela será recordada por estar fuertemente nutrida por el respeto a los derechos humanos, el manejo que Mbeki le dio a la PEE sudafricana consistió en la introducción de ideas de transformación socioeconómica y del desarrollo de los factores económicos; estos dos legados no han podido ser superados por la Pretoria de Zuma. ${ }^{42}$

\section{Indonesia y Vietnam: la cuota del sudeste asiático}

La crisis asiática de 1997 marcó las dinámicas del Sudeste Asiático, particularmente el contexto político-económico de Indonesia y Vietnam, donde, según Nguen (2007, p. 211), los modelos de desarrollo reflejan falta de madurez institucional traducida en el excesivo otorgamiento de garantías al sector público, sistemas financieros sobre regulados y débiles, auditorías pobres, tendencias oligárquicas y corrupción dispersa. Para Indonesia, líder del bloque ASEAN, la crisis de 1997 implicó la caída de Suharto (1967-1998); mientras que para Vietnam, liderado por Tran Duc Luong (1997-2006), conllevó la necesidad de gestionar un cambio político como resultado de una necesidad profundizada también por fuertes traumatismos sociales (Zakaria y Baladas, 1999). Indonesia y Vietnam tuvieron que implementar cambios estructurales internos a partir de las recomendaciones del FMI y del BM, así que fortalecieron la cooperación comercial y financiera y concibieron un modelo de interacción intracomunitaria sin injerencia en asuntos estatales domésticos (Dieter, 2009, p. 87). En ese contexto, la crisis de 1997 marcó el viraje de las PEE de los dos tigres asiáticos.

\footnotetext{
39 Tendencia opuesta a la de Mandela en los noventa, pues Sudáfrica negoció un acuerdo comercial con la UE (1996) y varios APPRI en los noventa (59\% se negoció en esa época). (UNCTAD Database, 2013). ${ }^{40}$ Como la manufactura, mediante preferencias locales y medidas proteccionistas a favor de sectores estratégicos y por el limitado desempeño económico alcanzado.

${ }^{41}$ Kgalema Petrus Motlanthe asumió el poder como presidente interino (2008-2009).

42 Landsberg, 2010a: 117; Landsberg, 2010b.
} 
Sin contar con una formación económica o política, la presidenta de Indonesia, Megawati Sukarnoputri (2001-2004) resaltó la necesidad de coordinar políticas en el bloque, cooperar y convertir a los países ASEAN en destinos de IED, para lo cual procuró mejorar los indicadores macroeconómicos y ajustar el déficit fiscal, terminando con la alta dependencia de Jakarta de las directrices del FMI. El sucesor de Megawati, Susilo Bambang Yudhoyono (2004-actualidad), político con formación militar, tuvo que lidiar con la visión proteccionista y la mirada liberal de sus asesores, lo que se reflejó en su equipo de gobierno: un ministro de la época de Suharto (Aburizal Bakrie) encabezó la cartera de comercio, mientras que tres economistas con una orientación pro-mercado con formación en EE.UU. fueron designados en posiciones clave. Ante el dilema ideológico, algunos indican que el mercado fue la orientación adoptada en Jakarta (Liddle y Mujani, 2005, p. 125) para direccionar su PEE, la cual priorizó a ASEAN sin dejar de lado otros grupos como APEC, la Comunidad del Este Asiático (EAC, por sus siglas en inglés) y el G20 (Kimura, 2011, p. 193). Así, es evidente que el actual gobierno indonesio bajo el liderazgo de Susilo Bambang Yudhoyono "es aún más agresivo" en el aprovechamiento de políticas pro-negociación de AII en coherencia con su política económica “abierta y neo-liberal” (Chandra, 2005, p. 552).

Tras ser un país fuertemente dependiente de la ex URSS durante los setenta y los ochenta, Vietnam optó por liberalizar su comercio tras la caída del bloque soviético en 1989, convirtiéndose el complejo proceso de reformas ${ }^{43}$ económicas en un componente esencial de los resultados actualmente alcanzados (Toh y Gayathri, 2004, p. 170) donde los líderes vietnamitas de la época se inspiraron atentamente en el ejemplo chino del momento (Painter, 2005).

Luego de adoptar una política de renovación (doi moi) en 1986, las autoridades vietnamitas apoyaron la liberalización económica a través de la restricción de la intervención pública en los asuntos privados de las empresas y las reformas estructurales para la modernización de su economía a través de la generación de industrias con vocación exportadora (Dinh, 2009; Beresford, 2008, p. 221), la promoción de la inversión extranjera como eje central de la transformación (McGrath, 1994) y el direccionamiento de su diplomacia hacia el fortalecimiento de relaciones sustanciales con economías avanzadas para movilizar recursos externos para el desarrollo del país. ${ }^{44}$ Las renovadoras estrategias de los finales de los ochentas produjeron una entrada significativa de capital

\footnotetext{
${ }^{43}$ Reformas de corte intervencionista que incluían elementos suaves como préstamos y tratamientos tributarios especiales para las empresas estatales, así como restricciones a las importaciones. ${ }^{44} \mathrm{El}$ nuevo rol que Dinh $(2009$, pp. 109, 109, 112) describe de Vietnam, también se refleja en el mayor protagonismo del país en ASEAN, así como en la generación de lazos más fuertes con Japón a partir, además, de la posición como miembro no permanente del Consejo de Seguridad de Naciones Unidas durante el término de 2008-2009. Lo anterior, claramente se ha traducido en la profundización de las relaciones de comercio e inversión de Japón con respecto a Vietnam.
} 
transnacional,45 lo que convirtió a la economía vietnamita en un destino atractivo de IED (Nguen, 2007, pp. 211-217).

El reconocimiento constitucional de Vietnam como una economía planificada, multi-componente (Constitución de la República Democrática de Vietnam, 1992) ${ }^{46}$ no impidió su membresía a ASEAN (1995) ni afectó el objetivo reiterado en 1992 de basar su política exterior en la diversificación y multidireccionalización, siendo su prioridad la cooperación regional y el mejoramiento de sus relaciones con los Grandes Poderes y los centros económicos. ${ }^{47}$ En medio de la tensión entre los anti-imperialistas y aquellos que apoyaban la integración con América (EE.UU.), la visión de los últimos prevaleció bajo la batuta de Tran Duc Luong, quien concretó un acuerdo económico con EE.UU., luego una alianza estratégica con Rusia (2001), y otros acuerdos con Japón e India en 2003 (Vuving, 2006, pp. 814-817). El acercamiento comercial de Hanói a Washington se concretó en la presidencia de Nguyen Minh Triet (2006-11), facilitado en buena parte por la membresía alcanzada a ASEAN en 1995, a APEC en 1998, y a la OMC en 2007 (Dosch, 2006, pp. 237, 246), y se tradujo en la suscripción de un acuerdo macro de comercio e inversión en 2007 con EE.UU. (USTR, 2013). Con ello, bajo el gobierno de Nguyen Minh Triet se demostró que el socialismo de mercado funciona, aunque en realidad Vietnam está adoptando un modelo de desarrollo liderado por el Estado a partir del uso de técnicas e instrumentos del neoliberalismo (Painter, 2005, p. 278) en el cual los actores privados ejercen presión para que el país se integre a la economía mundial y se diseñen regímenes de comercio e inversión que los beneficien (Dosch, 2006, p. 240).

Aunque la política exterior presidencialista vietnamita se ha visto afectada por la presión de nuevos actores, es evidente la transición paulatina de Hanói hacia la profundización de la integración y la multilateralización de las relaciones (Dosch, 2006, pp. 237-241). Ello a pesar de mantener su deferencia hacia Beijing y de que el Partido Comunista Vietnamita ha sido comandado desde 1991 por líderes anti-imperialistas (Vuving, 2006, pp. 819, 822).

En términos de las estrategias de negociación de Indonesia y Vietnam hacia la profundización del regionalismo y la suscripción de AII, ellas tienden a converger

45 Toda vez que Vietnam pasó de recibir ocho ETN (1988) a alcanzar ochocientas en 2007.

${ }^{46} \mathrm{~A}$ pesar de reconocerse expresamente la forma de producción y la propiedad común de los bienes expresados en colectividades e individualidades (artículo 15), el texto constitucional reconoce abiertamente el derecho a la propiedad individual (personas y organizaciones) y la figura de la nacionalización de las propiedades como un asunto excepcional (defensa nacional, seguridad e interés nacional) sujeto a una compensación de acuerdo con los precios del mercado (Artículo 23). ${ }^{47}$ Aunque hubo un fuerte discurso anti-imperialista y neo-patriótico liderado por la cabeza del Partido Comunista Vietnamita (Le Kha Phieu, 1997-2001) fortalecido por el acercamiento que buscaba con China (Vuving, 2006, p. 816). 
(Chandra, 2005, p. 545), ${ }^{48}$ con una fuerte tendencia de Hanói a profundizar la red de relaciones bilaterales con Japón (Dinh, 2009). Como países miembros de ASEAN, los dos países se benefician de la zona de libre comercio (Asean Free Trade Agreement, 1992) y de acuerdos suscritos con Australia-Nueva Zelanda (2009); China (2004, 2007); India (TLC, 2009) y Corea del Sur (TLC, 2006), mientas que extracomunitariamente, tanto Vietnam (2008) como Indonesia (2007) han suscrito un acuerdo con Japón (TLC).49

En términos generales, la tendencia hacia la convergencia de las PEE de Indonesia y Vietnam es clara. No obstante, el panorama es distinto al contrastar la estrategia negociadora con los resultados alcanzados en la atracción de IED a sus territorios (ver Tabla 2). Ligada a la necesidad de recuperarse de los efectos negativos sufridos por la crisis financiera de 1997, Indonesia implementó las medidas estructurales de corte macroeconómico y financiero sugeridas por el BM y el FMI, y profundizó la integración subregional en el bloque ASEAN (Chandra, 2005, pp. 545, 548).

Como muestra de ello, durante los noventa se inició una campaña de negociación de AII reflejada en la negociación de 65\% de los APPRIs que han sido notificados a la UNCTAD Database (2013). Por el contrario, el nuevo milenio marcó el inicio de una política de relativa prudencia al contrastarla con la tendencia de la década pasada. Sin embargo, la llegada de inversión extranjera a Indonesia ha sido principalmente a industrias extractivas y aceite de palma (WTO, 2013).

En cuanto a los AII suscritos por Vietnam, al igual que Indonesia, el mayor dinamismo se reportó durante los noventa. La tendencia vietnamita de suscribir diversos APPRI ha sido menos drástica que la táctica indonesia de tener en vigor muchos AII. Sin embargo, los noventa marcaron el inicio del boom en la formulación de reglas claras en materia de IED. Así, 35\% de los 58 APPRI suscritos por Vietnam, a la fecha, se materializó a lo largo de los noventa (UNCTAD Database, 2013).

En términos de socios comerciales comunes, la membresía de Indonesia y Vietnam a ASEAN claramente ha facilitado la celebración de acuerdos comerciales en bloque (salvo Indonesia y la actual negociación con los países EFTA). Tendencia similar se encuentra en la suscripción de variados APPRI, pues ambos países han suscrito acuerdos de esa naturaleza con 40 interlocutores comerciales comunes..$^{50}$ En ese sentido, se constata nuevamente que la tendencia de los CIVETS de suscribir tratados con socios

\footnotetext{
${ }^{48}$ Lo que se tradujo también la entrada significativa de IED a inicios de los noventa en Indonesia y Vietnam, al punto de que antes de la crisis de 1997, 30\% del PIB correspondía a ingresos por ese rubro (Nguen, 2007, p. 211).

${ }^{49}$ Aunque Indonesia está negociando un acuerdo comercial con los países EFTA. (UNCTAD Database, 2013).

${ }^{50}$ Siendo Argentina y Chile los únicos interlocutores latinoamericanos comunes con los cuales Indonesia y Vietnam han suscrito APPRI. (UNCTAD Database, 2013).
} 
considerados como estratégicos durante los noventa, principalmente, y buena parte de la primera década del siglo XXI, aplica para el caso de Indonesia, Sudáfrica y Vietnam, siendo Colombia el país más conservador.

\section{Egipto-Turquía: potencias regionales con inestabilidad política}

Luego de la independencia de los británicos en 1922, Egipto se convirtió en punto de contacto entre África, Asia y Medio Oriente con el mundo occidental, lo cual se tradujo en el rol de Egipto en la creación de la Liga de los Países Árabes (1945) y en su liderazgo dentro del grupo de los Países No Alineados. Luego del intento poco exitoso de Nasser (1956-1970) de aplicar medidas de apertura económica, Muhammad Anwar as-Sadat llegó al poder (1970-1981) eliminando coercitivamente las ideas nasserianas para dar paso al activo rol de la política exterior económica egipcia (Farah, 2009, p. 37).

En el contexto de una crisis económica, y bajo la administración de Muhammad Hosni Mubarak (1981-2011), se adoptó la open door policy egipcia, lo que sumado a la hiperinflación, el bajo crecimiento económico y los pocos ingresos para su población (1986-1993), marcaron el terreno para el siglo XXI. Concentrado en la necesidad de realizar reformas agresivas con el fin de atraer IED a su territorio, de retornar al FMI, al BM, de beneficiarse de los programas de asistencia financiera (1991), y de ingresar a la OMC (1995), el modelo mubarakiano, en términos de Farah (2009, p. 43), no le permitió a Egipto convertirse en receptor de importantes flujos de IED, a lo cual se suma el malestar social por la profundización de la pobreza y la inequidad. De ahí que el Egipto de Mubarak sea catalogado por Fürtig (2006, p. 13) como una potencia regional bastante debilitada a partir de los radicales cambios en el ambiente político del país.

A partir de la tendencia neoliberal de los nuevos tomadores de decisión egipcios, pertenecientes al Partido Nacional Democrático (PND), se establecieron alianzas público-privadas que reemplazaron los esquemas de élites pasadas. Así se formó un nuevo gabinete marcado por una clara inclinación hacia los negocios internacionales. Bajo la batuta del primer ministro Ahmad Nazif (2004-2011) se profundizaron reformas internas profundas en materia comercial para hacer la transición de Egipto hacia una economía de mercado atractiva para las ETN, mediante la inclusión en su gabinete de tecnócratas y hombres de negocios. A pesar de tales cambios, para Farah (2009, pp. 1, 3), el Egipto moderno sigue debatiéndose entre la visión tradicional y las ideas de la nueva élite.

Ante los resultados negativos, Hosni Mubarak proclamó una Política Única (2003) para acelerar un paquete de reformas estructurales para mejorar el clima egipcio de negocios. Bajo el mando de un hombre de negocios, las carteras involucradas en el diseño de la política exterior egipcia (comercio, finanzas e inversión) conformaron el nuevo equipo e implementaron ambiciosas reformas para atraer IED al territorio. 
$\mathrm{Al}$ igual que Indonesia, Vietnam y Sudáfrica, Egipto presentó una tendencia hacia la suscripción de AII en los noventa principalmente ya que el 71\% de los 100 APPRI fueron negociados en esa década. Por el contrario, se reporta una tendencia reservada, por razones históricas, durante los setenta (5 APPRI) y ochenta (4 APPRI); y muy activa en el siglo XXI (20 APPRI).

Por otro lado, a diferencia de Indonesia y Vietnam, la membresía de Egipto a ciertos procesos de integración no ha significado una posición de bloque para la suscripción de acuerdos comerciales regionales. Si bien los egipcios se benefician de la unión aduanera creada en el Mercado Común de África Oriental y Meridional (COMESA, por sus siglas en inglés), ${ }^{51}$ del Área Pan Árabe de Libre Comercio (PAFTA, por sus siglas en inglés) y de un acuerdo de alcance parcial (Protocol on Trade Negotiations: PTN, por sus siglas en inglés), bilateralmente las relaciones más profundas se han trazado con la Unión Europea (2004), EFTA y Turquía (2007).

Así pues, Turquía y Egipto, dentro del marco CIVETS, se consolidan como socios comerciales geoestratégicamente ubicados que conectan regiones y culturas. Turquía se ubica como punto de conexión de tres áreas de gran importancia estratégica: los Balcanes, la región del mar Caspio y Medio Oriente (Larrabee y Lesser, 2003, p. ix). Considerado en la arena internacional como un Estado clave, ${ }^{52}$ Turquía, como muchos PED, adoptó en los ochenta paquetes de estabilización y ajuste estructural propuestos por instituciones dirigidas por Washington (FMI, BM, Departamento del Tesoro de EE.UU.) y dadas a conocer por Williamson como el "Consenso de Washington”. Ante la urgencia de ajustarse a los estándares europeos de manera que la economía turca fuera compatible con aquellos, tuvo que adoptarse otro plan de austeridad ante la crisis de 1994 (Nas, 2008, pp. 51-67).

El nuevo milenio recibió a Turquía con dos crisis (2000, 2001), escándalos de corrupción y enfrentamientos políticos entre el presidente Necdet Sezer y el primer ministro Ecevit. Aplicado el plan de ajuste sugerido por el FMI (7/12/200o), se limaron asperezas para que Turquía pensara en la posibilidad de ingresar al bloque europeo (Nas, 2008, pp. 86, 91). Bajo el liderazgo de Kemal Derviş (ex funcionario turco del BM) estuvo el futuro económico del país, traducido en la propuesta de un Programa de Transición hacia una Economía Fuerte, facilitando, según Nas (2008, p. 102), la convergencia de la política turca a los estándares europeos y el inicio del fin de las crisis (08/2001), a

\footnotetext{
${ }^{51}$ COMESA la componen Burundi, Comoras, Congo, Yibuti, Eritrea, Etiopía, Kenia, Libia, Madagascar, Malaui, Mauricio, Ruanda, Seychelles, Sudán, Suazilandia, Uganda, Zambia y Zimbabue.

52 Tomando indicadores como el tamaño de la población, ubicación geográfica y potencial económico y militar, que podría traducirse en la capacidad de afectar la estabilidad regional e internacional. Chance, R., Hill, E. y Kennedy P., citados por Larrabee y Lesser (2003, p. 2).
} 
lo cual deben sumarse los esfuerzos por fortalecer las alianzas público-privadas y por fortalecer la independencia del banco central de ese país. ${ }^{53}$

Con ese contexto, en el siglo XXI han predominado períodos de crecimiento y decrecimiento económicos, principalmente a partir del retroceso causado por los ataques a las Torres Gemelas, que han estado marcados por altas tasas de inflación (55\%-106\%) y mayor relacionamiento con el FMI (Togan y Ersel, 2005). Así, las fuerzas económicas y los efectos negativos de la crisis han hecho que en Turquía se consolide la comunidad de negocios con influencia en la formulación de la política exterior, sin dejar de lado el rol del Fondo, lo que ha llevado al replanteamiento de la política exterior turca en términos económicos (Larrabee y Lesser, 2003, pp. 1, 2, 7, 11).

La europeización de Turquía, como diría Terzi (2010, p.1), lograda a partir del deseo de ese país por convertirse en miembro pleno de la Unión Europea, ha presionado a los tomadores de decisión a implementar reformas económicas que transformen el objetivo estatal de ingresar al bloque europeo en una posibilidad real. ${ }^{54}$ Así, el interés de ETN por localizarse en territorio turco ha obedecido más al potencial del mercado y a su tamaño, su posición geográfica, mano de obra barata y calificada, a lo cual deben sumarse los estímulos domésticos ${ }^{55} \mathrm{y}$ regionales liderados por ese país para ser un atractivo destino de IED (Berzok y Turk, 2009, p. 2). Sin embargo, el riesgo derivado de las actuales crisis financieras, económicas y especialmente políticas sigue siendo un elemento a mejorar para el caso de Turquía -y Egipto-, mucho más cuando el riesgo político ha presionado la salida de capital extranjero (ver Tabla 2).

Guardando coherencia con la tendencia marcada hacia la suscripción de AII en los noventa por parte de los otros países analizados, la política exterior turca también se volcó hacia la necesidad de profundizar sus relaciones comerciales bilaterales más que regionales. Dentro de su apuro por ser considerado un país del bloque europeo, y de paso afianzar las relaciones comerciales con éste mediante el perfeccionamiento de una unión aduanera (1995), Ankara aprovechó su membresía a la Organización para la Cooperación Económica

\footnotetext{
${ }^{53}$ Ley 4651, 2001 (Nas, 2008, pp.134, 135).

${ }^{54}$ Tras la solicitud inicial de Turquía en 1959, siguió la solicitud de membrecía total al bloque (1987) que llevó a la conformación de una unión aduanera Turquía-UE a ser consolidada en 2001 y a la presentación de ese país por parte de la Comisión Europea al Concejo Europeo sobre el inicio de negociaciones formales con el país euroasiático (Terzi, 2010, p. xvii). A modo de ejemplo, se tiene la adopción de los principios generales de la política comercial comunitaria europea en temas puntuales (antidumping, competencia, propiedad intelectual, entre otros).

${ }^{55}$ Como puede ser el estímulo directo propuesto por las autoridades nacionales turcas, traducido en la necesidad de ajustarse a los estándares europeos en materia de promoción y protección a la IED. Así, contar con condiciones adecuadas de protección y reglas de juego claras fue la razón de ser de la ley sobre IED (Ley 4875, 2003).
} 
Tabla 2

Entrada de IED neta a los países CIVETS (2000-2011) - \% PIB

\begin{tabular}{|l|l|l|l|l|l|l|l|l|l|l|l|l|}
\hline \multicolumn{1}{|c|}{ País } & $\mathbf{2 0 0 0}$ & $\mathbf{2 0 0 1}$ & $\mathbf{2 0 0 2}$ & $\mathbf{2 0 0 3}$ & $\mathbf{2 0 0 4}$ & $\mathbf{2 0 0 5}$ & $\mathbf{2 0 0 6}$ & $\mathbf{2 0 0 7}$ & $\mathbf{2 0 0 8}$ & $\mathbf{2 0 0 9}$ & $\mathbf{2 0 1 0}$ & $\mathbf{2 0 1 1}$ \\
\hline Colombia & 2.4 & 2.6 & 2.2 & 1.8 & 2.6 & 7 & 4.1 & 4.6 & 4.2 & 3 & 2.4 & 4.1 \\
\hline Indonesia & -2.8 & -1.9 & 0.1 & -0.3 & 0.7 & 2.9 & 1.3 & 1.6 & 1.8 & 0.9 & 2.4 & 2.1 \\
\hline Vietnam & 4.2 & 4 & 4 & 3.7 & 3.5 & 3.7 & 3.9 & 9.4 & 10.5 & 7.8 & 7.5 & 6 \\
\hline Egipto & 1.2 & 0.5 & 0.7 & 0.3 & 1.6 & 6 & 9.3 & 8.9 & 5.8 & 3.6 & 2.9 & -0.2 \\
\hline Turquía & 0.4 & 1.7 & 0.5 & 0.6 & 0.7 & 2.1 & 3.8 & 3.4 & 2.7 & 1.4 & 1.2 & 2.1 \\
\hline Sudáfrica & 0.7 & 6.1 & 1.3 & 0.5 & 0.3 & 2.6 & -0.1 & 2 & 3.5 & 1.9 & 0.3 & 1.4 \\
\hline
\end{tabular}

Fuente: World Bank Indicators

(ECO) para suscribir un acuerdo de complementación económica (1992), ${ }^{6}$ mientras que, bilateralmente, optó por negociar varios TLC en los noventas. ${ }^{57}$ Continuando con su interés de insertarse en el contexto económico mundial, Turquía adoptó una política agresiva de suscripción de TLC, ${ }^{8}$ así como de APPRI. ${ }^{59}$ La tendencia se mantuvo durante el siglo XXI, en buena medida debido a la crisis experimentada por algunos países europeos (Öniş, 2010, p. 12), aunque con un poco de prudencia bajo los gobiernos de Necdet Sezer (2000-2007) y de Abdullah Güll (2007-actualidad). ${ }^{60}$

A pesar de las claras diferencias entre los regímenes de Necdet y Güll en el manejo de la política exterior, ${ }^{61}$ Ankara tuvo que encontrar la manera de suplir la dependencia del mercado europeo (en crisis desde inicios del siglo XXI, lo que despertó el interés por el Medio Oriente, África del Norte y lo que era la región soviética). De hecho, la crisis financiera facilitó la salida de capital turco, el surgimiento de centros de industrialización y acumulación de capital como actores centrales en las iniciativas de la PEE del país (como TOBB, MÜSİAD, TUSKON). De igual forma, la economía y el comercio se convirtieron en un elemento práctico de la política exterior de Ankara en la cual se tienen en cuenta las iniciativas para la diversificación de las relaciones internacionales con el fin de suplir el vacío derivado de la crisis europea (Öniş, 2010, p. 12, 13).).

Es posible señalar que Turquía, bajo los gobiernos de Necdet Sezer y de Abdullah Güll, ha moldeado su política exterior a partir de la interacción del Estado con grupos económicos domésticos. No obstante, cabe resaltar que fue a partir de 2002 cuando se decidió que las relaciones económicas y comerciales debían mejorarse, de modo que el

\footnotetext{
${ }^{56}$ Afganistán, Azerbaiyán, Irán, Kazajistán, Kirguistán, Pakistán, Tayikistán, Turkmenistán y Uzbekistán.

57 Con EFTA (1991), Israel (1996) y la ex República Yugoslava de Macedonia (1999).

58 Bosnia-Herzegovina y Croacia (2002), en 2004 con la Autoridad Palestina, Marruecos, Túnez y Siria, Egipto (2005), Albania (2006), Georgia (2007), Montenegro (2008) y, más recientemente, con Chile y Serbia (2009).

${ }^{59} \mathrm{El} 56 \%$ de los 82 acuerdos fueron suscritos en los noventas.

${ }^{60}$ De los APPRI, 35\% fue negociado y suscrito en el nuevo milenio. (UNCTAD Database, 2013).

${ }^{61}$ Para Necdet la prioridad de gobierno estuvo en los asuntos domésticos, a diferencia de Güll quien ha mostrado un interés por asuntos internacionales (Öniş, 2010, p. 10).
} 
comercio y la inversión fueron considerados como instrumentos de la política exterior turca acompañados de la activa relación entre el Estado y la comunidad de negocios. Como segunda iniciativa se apoyó el surgimiento de una "burguesía conservadora" como una nueva categoría en el mundo de negocios que no sólo creara su centro de negocios sino que explorara nuevos mercados. Entonces, Ankara promueve activamente la participación de los grupos económicos en el proceso de conformación de la política exterior mediante la creación de plataformas de interacción con los tomadores de decisión mediante contacto directo; eventos; y representación directa en reuniones y negociaciones (Atli, 2011, pp.110, 116, 121).

\section{Contrastando resultados}

Las PEE de los CIVETS siguen lineamientos generales similares en términos de su formulación, la estrategia negociadora adoptada y los estándares internacionales que cada Estado ha procurado reconocer en los AII que ha suscrito. Resulta evidente para todos los países CIVETS la importancia que tienen las variables sistémicas en el perfilamiento de sus PEE lo que se expresó en la necesidad de ajustar sus políticas domésticas a la lógica neoliberal (siendo decisivo el rol del FMI y del BM para el caso de Egipto y Turquía principalmente) en los noventas.

Como elemento transversal, se identificó la influencia de organizaciones como la OMC y UNCTAD en la forma como los países CIVETS han adoptado la decisión de reconocer en distintos AII los principios en materia comercial reconocidos en GATT/ OMC y los principios propios en materia de inversión extranjera que promueve la UNCTAD. Lo anterior explica la tendencia observada de todos los países del acrónimo de adelantar agresivas estrategias de negociación para consolidar acuerdos con socios considerados estratégicos. En este aspecto el caso colombiano viene a ser la excepción, pues todos los APPRI notificados a UNCTAD fueron suscritos en el siglo XXI, a diferencia de la tendencia constatada para los casos de Indonesia, Vietnam, Egipto, Turquía y Sudáfrica de alcanzar acuerdos durante los noventas y en el siglo XXI.

En todo caso, los países CIVETS han fijado el liderazgo de las negociaciones de los AII a la cartera de comercio, considerando a los ministerios de relaciones exteriores como entes de apoyo. ${ }^{62}$

El peso de las ideas en las PEE de los países se ha reflejado en la determinación de los principales tomadores de decisión de internacionalizar sus economías Adicionalmente, los países CIVETS adelantaron cambios en periodos cronológicos similares. Si bien Colombia había considerado la necesidad de insertarse al comercio mundial desde los ochentas, el énfasis en la inversión fue desarrollado en el siglo XXI a doble nivel: (i)

${ }^{62}$ Según se desprende de las páginas de Internet consultadas. 
generando confianza al inversionista local (2002-2006); y (ii) procurando estabilidad y certeza jurídica a grupos económicos transnacionales (2006-2010). En la actualidad, bajo la fuerte lógica geoeconómica del presidente Santos (2010-actual), y la adopción de la "vertiente ideológica liberal" de su equipo de gobierno (Pastrana y Vera, 2012, p. 67), Bogotá ha procurado integrar los dos niveles con la necesidad de desarrollar el pilar de la "relevancia internacional" intentando involucrar a los grupos de negocios domésticos en la construcción de la PEE.

La experiencia sudafricana en la construcción de su PEE bajo Mandela-Mbeki fue "revolucionaria" en la medida que, luego del apartheid, Mandela procuró dotarla de contenido a través de la incorporación de sociedad en los procesos domésticos para que luego ésta lograra beneficiarse de las dinámicas globales en materia comercial; mientras que Mbeki, con un enfoque más geoeconómico, procuró involucrar elementos socioeconómicos a la política exterior de Pretoria en búsqueda del aprovechamiento de las ventajas geoestratégicas de Sudáfrica.

Para el caso indonesio-vietnamita, sus PEE estuvieron fuertemente marcadas por los efectos de la crisis financiera de 1997, lo que generó la necesidad de profundizar las relaciones de inversión con sus pares en la región en el marco de ASEAN. Si bien puede extenderse la tendencia descrita al caso vietnamita, debe reconocerse que la estrategia de Hanói de ser considerado como miembro pleno en el bloque asiático evidentemente facilitó el ingreso a otras organizaciones como la Asea-Pacific Economic Cooperation (APEC, por sus siglas en inglés) y la OMC, y coadyuvó a la rápida consolidación de una compleja red de acuerdos internacionales en comercio e inversión. ${ }^{63}$

Para el caso egipcio, su PEE está fuertemente nutrida por la visión complementaria de tecnócratas del PND con una fuerte tendencia neoliberal, y las necesidades identificadas por la comunidad de negocios del país, lo que se refleja en la suscripción de ciento cincuenta AII reportados (UNCTAD Database, 2013) principalmente bajo el régimen de Mubarak (1981-2011); además del hecho de que Egipto es el único país del acrónimo CIVETS que ha suscrito APPRI con los otros países (excepto con Colombia). Sin embargo, los esfuerzos de El Cairo por generar estabilidad y confianza a grupos económicos transnacionales han sido insuficientes debido a la inestabilidad política, los disturbios civiles, los retos existentes en materia de seguridad y los eventos políticos más recientes en el Medio Oriente. ${ }^{64}$

Turquía, por otro lado, ha enfocado su PEE con el fin de superar las crisis financieras estructurales, a partir de las recomendaciones de distintas instituciones financieras

\footnotetext{
${ }^{63}$ En ese mismo sentido, ver Dosch (2006).

${ }^{64}$ En Egipto la salida de IED ha sido evidente. Se pasó de U\$2,1 billones en julio2010-marzo 2011 a tan sólo U\$218 millones julio 2011-marzo 2012 (MIGA, 2012. Disponible en: http://www.miga. org/documents/WIPR12.pdf ). Turquía, por el contrario, no ha experimentado efectos tan negativos como los señalados para Egipto.
} 
internacionales (IFI), y alcanzar su admisión como miembro pleno de la UE. Los anteriores factores no sólo han generado el fenómeno de europeización del que habla Terzi (2010), sino la decisión de Ankara de nutrir su PEE con una visión de negocios.

El análisis de las PEE adoptadas por los países CIVETS debe acompañarse del elemento bandera que llevó a The Economist a crear el acrónimo. Así, resulta indispensable conocer el resultado de la implementación de estrategias de atracción de flujos de IED de cada una de esas economías incluyendo el año 2011, a pesar de la delimitación cronológica planteada en la investigación.

Los efectos de la crisis hipotecaria norteamericana (2007) y de la actual crisis europea profundizada en Chipre, Portugal, Irlanda, Grecia y España, se reflejaron en la menor recepción de flujos de IED para todos los países CIVETS. Egipto, después de la caída más fuerte de su historia (2003: 0,3\% del PIB), logró recuperarse (2006, 2007); pero, hacia el año 2011 reportó desinversión (-0,2\% del PIB), sin mostrar signos de recuperación. En cuanto a Turquía, la situación estructural de crisis e inestabilidad se ha traducido en el menor peso de la IED en su PIB a lo largo del SXXI. A pesar de que el comportamiento de la IED en la economía turca no ha sido espléndido, ha sido constante (2005-2011). Comparativamente, Vietnam ha sido el país menos golpeado por las crisis mencionadas; mientras que Indonesia, a pesar de ser el único en el grupo CIVETS que ha reportado desinversión consecutivamente (2000-2003), se ha mantenido constante.

Tras contrastar a Colombia y Sudáfrica es evidente que los resultados en términos de peso de la IED en el PIB son positivos para Colombia desde el año 2002. ${ }^{65}$ Sin embargo, debe resaltarse que Pretoria se ha propuesto aprovechar los resultados de la PEE como motor para superar problemas sociales estructurales fundamentados en motivos raciales y de género (pobreza, desempleo, discriminación y falta de acceso a distintas oportunidades). Aun así, los resultados en términos de inequidad son más esperanzadores para el país andino. ${ }^{66}$

En síntesis, el siglo XXI significó la recepción de los niveles más altos de entrada de IED neta para Vietnam (2008), Egipto (2006) y Colombia (2005) y el inicio de una etapa de recuperación para Indonesia (2010).

\section{Conclusiones}

Al tratarse CIVETS de un acrónimo creado luego de nueve años de los BRIC, bien pudo haberse esperado que entre países tan distintos se hubieran creado plataformas de

${ }^{65}$ En 1995 el ingreso de IED a Colombia representaba el 1\% del PIB, mientras que para Sudáfrica equivalía al 0,8\%. Para el año 2010 la diferencia se mantiene (Colombia: 2,4\% PIB; Sudáfrica: $0.3 \%)$. (World Bank Indicators).

${ }^{66}$ Sudáfrica presenta el ambiente más preocupante en términos de inequidad (63,1 en 2009), seguido del país suramericano ( 56,7 en ese año). En contraste con los datos más recientes reportados para Indonesia (36,8 en 2009) y Vietnam (37, 6 en 2008). (World Development Indicators, 2011). 
diálogo en asuntos de inversión (elemento bisagra del grupo). Es evidente que tan sólo para el caso colombiano el acrónimo fue considerado como una de las prioridades de gobierno para el período 2010-2014, sin que existan señales de que los líderes de esas economías estén dispuestos a generar espacios de diálogo y coordinación multilateral. Así que el autoproclamado liderazgo de Bogotá dentro del grupo no ha trascendido las consignaciones teóricas recogidas en los Principios y Lineamientos de la política exterior colombiana (Ministerio de Relaciones Exteriores, 2010). La actual aproximación del país hacia algunos pares del acrónimo ha sido en el plano bilateral, principalmente con fines comerciales y de inversión, a través de la negociación de AII.

Tras el análisis comparado de las economías emergentes agrupadas en el acrónimo CIVETS se constató el fenómeno de convergencia de sus PEE, explicada a partir de elementos sistémicos (históricos procesos de transición económica; superación de situaciones de crisis e internacionalización de las economías) y cognitivos (las ideas). Las situaciones de crisis fueron el elemento bisagra identificado para los CIVETS. Así, para Colombia la crisis de la deuda externa de los ochentas implicó la adopción de lineamientos neoliberales hacia los noventas en gran medida por recomendación de las IFI. Para Sudáfrica la prioridad fue la superación de las históricas problemáticas domésticas derivadas del apartheid, de modo que la inclusión social y la superación de la discriminación racial fueron prioridades de gobierno; para luego adoptar estrategias de relacionamiento internacional y de profundización de las dinámicas bilaterales para darle un rumbo a la PEE. En el caso de Indonesia y Vietnam, la crisis de 1997 conllevó a la necesidad de apostarle a la integración en el marco de ASEAN, fortaleciendo escenarios de construcción y de confianza. Hanói con el doi moi enfocó su esfuerzo por ingresar a ASEAN, mejorar su clima de inversión y fundar su crecimiento económico en la entrada de inversión extranjera sin desconocer su calidad de economía planificada, mientras que Jakarta cedió a su deseo de profundizar las relaciones comerciales con países intracomunitarios, dando paso a la tendencia generalizada de recurrir a la negociación de AII con países no miembros de ASEAN (Chandra, 2005, pp. 542, 552).

La Turquía del siglo XXI, en su intento por superar la ya estructural situación de crisis financiera y de ingresar al bloque europeo, aprovechó los programas de ajuste sugeridos por las IFI y reconoció la importancia de nutrir su PEE con la visión pragmática de los grupos económicos domésticos. De manera similar, Egipto procuró tener una PEE activa para lo cual mejoró los indicadores de su clima de inversión y adelantó una agresiva estrategia de negociación de AII. Sin embargo, la inestabilidad política (2011-actualidad) ha limitado las proyecciones económicas y ha activado la salida de capital foráneo de ese país.

Otro factor explicativo del fenómeno de convergencia de las PEE de los países CIVETS es el elemento cognitivo. Atendiendo la formación y las ideas de los tomadores 
de decisión de los países involucrados, se reconoce que la presión para adoptar las PEE también puede provenir de las ideas que, según Drezner (2001, p. 57), han sido comúnmente aceptadas en organizaciones internacionales. Bajo esa lógica puede explicarse la tendencia de los países CIVETS de adelantar reformas internas para responder mejor a los intereses de las IFI (FMI, BM) y de grupos económicos transnacionales en su interés por establecerse en sus territorios; así como promover negociaciones comerciales para no quedarse rezagado en la ya compleja red de AII.

En el caso colombiano, el objetivo de Uribe de mejorar los indicadores de Colombia en los rankings internacionales y la iniciativa de Santos de no sólo continuar con las negociaciones comerciales promovidas por su antecesor, sino de mejorar el posicionamiento de Colombia a nivel regional (y global) alcanzando la "relevancia internacional" del país incidieron en el manejo que en Bogotá se le ha dado a la política exterior presidencialista en temas económicos. De modo similar al caso colombiano, la Sudáfrica de Mandela estaba interesada por dejar de ser un país económicamente asilado; mientras que el giro dado a la PEE de la nueva Sudáfrica bajo Mbeki respondió en gran medida a la formación del mandatario; siguiendo aún ausente el rol protagónico que podría asumir el actual presidente Jacob Zuma.

Si bien la influencia de los cambios estructurales sugeridos por las IFI a partir de la crisis de 1997 fue decisiva en el caso indonesio y vietnamita, las ideas de las élites en la construcción de las PEE también jugaron un papel importante. La influencia de una mirada neoliberal para el caso de Jakarta significó la adopción de una PEE agresiva (decidida a superar la tradición de más de treinta años del régimen de Suharto) y ajustada a los requerimientos económicos globales y a las demandas de grupos económicos domésticos; mientras que la PEE de Hanoi, perfilada por la "élite burocrática" fue permeada -aunque en menor medida con respecto al caso indonesio- por actores privados y públicos internos. Así, no sólo la tradicional élite vietnamita es la responsable de estructurar la PEE (cartera de relaciones exteriores), sino que entes públicos (agencias de comercio, planeación e inversión), los intereses de actores privados (empresarios) -a través del lobby al partido y al gobierno-, y la influencia de los tanques de pensamiento vietnamitas, también han permeado la construcción de esa política (Dosch, 2006, p. 239, 240).

En cuanto a Egipto y Turquía, se constató la influencia de una visión neoliberal por parte de los tomadores de decisión y las élites; así como la necesidad de incorporar a sus PEE el pragmatismo propio de la comunidad de negocios. Sin embargo, desde la salida de Mubarak (02/2011) la inestabilidad política experimentada en El Cairo se ha reflejado también en la aminorada influencia de los flujos de inversión extranjera en la economía egipcia.

Finalmente, bajo el período de estudio, se constató que el fenómeno de convergencia de las PEE de los países CIVETS no ha tenido relación con la creación del acrónimo. 
Por el contrario, se hizo evidente a través de la variable de estrategias de negociación de AII que la membrecía de tales países a entes interestatales como el FMI, BM, UNCTAD y organizaciones como la OMC influyó fuertemente en la tendencia de los CIVETS por insertarse en la ya densa red de tratados internacionales a nivel comercial y de inversión.

\section{Referencias Bibliográficas}

Alden, C. y Vieira, M. (2007). "La nueva diplomacia del Sur: Brasil, Sudáfrica, India y el trilateralismo”. En: Toklatian, J. (Ed.). India, Brasil y Sudáfrica: El impacto de las nuevas potencias regionales. Buenos Aires: Libros del Zorzal, pp. 137-168.

Allen, M. (2006). Globalization, Negotiation, and the Failure of Transformation in South Africa: Revolution at a Bargain. Nueva York: Palgrave Macmillan.

Atli, A. (2011). Businessmen as Diplomats: The Role of Business Associations in Turkey's Foreign Economic Policy. Insight Turkey, 13 (1), 109-128.

Beresford, M. (2008). Doi Moi in Review: Building Market Socialism in Vietnam. Journal of Contemporary Asia, 38 (2), 221-243.

Berzok, L. y Turk, S. (2009). Locational Preferences of FDI Firms in Turkey: A Detailed Examination of Regional Determinants. European Planning Studies, 17 (8), 1243-1256.

Büte, T. y Milner, H. (2008). The Politics of Foreign Direct Investment into Developing Countries: Increasing FDI through International Trade Agreements? American Journal of Political Science, 52 (4), 741-762.

Chase, R., Hill, E. y Kennedy, P. (1996). Pivotal States and U.S. Strategy Essay. Foreign Affairs, 35 (1), 33-51.

CIA World Factbook - Central Intelligence Agency (s.f.). Disponible en: https://www.cia.gov/library/publications/the-world-factbook/

CIADI - International Centre for Settlement of Investment Disputes (2013). Disponible en: https://icsid.worldbank.org/ICSID/FrontServlet?requestType=ICSIDDocR H\&actionVal=ShowDocument\&language $=$ English

Cohen, B. (1990). The Political Economy of International Trade. International Organization, 44 (2), 261-281.

Chandra, A. (2005). Indonesia and bilateral trade agreements. The Pacific Review, 18 (4), 541-565.

Dieter, H. (2009). Changing patterns of regional governance: from security to political economy? The Pacific Review, 22 (1), 73-90.

Dinh, T. (2009). Vietnam-Japan Relations in the Context of Building an East Asian Community. Asia-Pacific Review, 16 (1), 100-129. 
Dosch, J. (2006). Vietnam's Asian membership Revisited: Golden Opportunity or Golden Age. Contemporary Southeast Asia, 28 (2), 234-258.

Draper, P. (2011). For how long can South Africa "punch above its weight"? European View, 10, 207-2013.

Drezner, D. (2001). Globalization and Policy Convergence. International Studies Review, 3 (1), 53-78.

Flemes, D. (2007). Conceptualising regional power in international relations: Lessons from the South African case, Working Paper No. 53. GIGA. Disponible en: http:// papers.ssrn.com/sol3/papers.cfm?abstract_id=1000123

Flemes, D. (2012). "La política exterior colombiana desde la perspectiva del realismo neoclásico”. En: Jost, S. (Ed.). Colombia: ¿Una potencia en Desarrollo? Escenarios y desafios para su política exterior. Bogotá: Kas, pp. 19-37.

Farah, N. (2009). Egypt's Political Economy: Power Relations in Development. El Cairo: American University in Cairo Press.

Frieden, Jeffry A. y Lisa Martin. (2002). "International Political Economy: Global and domestic Interactions”. En: Katznelson, I. y Milner, H. (Eds.). Political Science: The State of the Discipline. Nueva York: W.W., pp. 118-146

Fürtig, H. (2006). Conference Paper. "Regional Powers in Asia, Africa, Latin America, the Near and Middle East. Hamburgo: GIGA.

Goldstein, J., Rivers, D., y Tomz, M. (2007). Institutions in International Relations: Understanding the Effects of the GATT and the WTO on World Trade. International Organization, 61 (1), 37-67.

Guerra-Barón, A. (2013). The Brazilian and the Colombian experiences from the debt crises of the eighties as an extension of transnational network policies. Presentación realizada en "Financial Stability and Energy Security in the Americas and Europe, Boston, 13-14, febrero.

Guerra-Barón, A. (2012a). “Colombia y Brasil: un análisis desde la perspectiva económica”. En: Pastrana, E., Jost, S. y Flemes, D. (Eds.). Colombia y Brasil: ¿̇socios estratégicos en la construcción de Suramérica? Bogotá: Editorial Javeriana, pp. 387-420.

Guerra-Barón, A. (2012b). Los CIVETS en el horizonte de la política exterior colombiana. En: Jost, S. (Ed.). Colombia: cuna potencia en desarrollo? Escenarios y desafios para su política exterior. Bogotá: KAS, pp. 371-390.

Guy, A. (2000). New South Africa. Nueva York: Palgrave Macmillan. 
Hayter, S., Reinecke, G. y Torres, R. (2001). South Africa: Studies on the Social Dimension of Globalization. Ginebra: International Labour Organization.

Hirsch, A. (2005). Season of Hope: Economic Reform under Mandela and Mbeki. Ottawa: University of KwaZulu-Natal Press.

Hoskisson, R., Eden, L., Chung, M. y Wright, M. (200o). Strategy in Emerging Economies. The Academy of Management Journal, 43 (3), pp. 249-267.

IFC - International Finance Coorporation. (2010). Disponible en: http://iab.worldbank. org/ /media/FPDKM/IAB/Documents/IAB-report.pdf

Katzenstein, P. (1977). Introduction: Domestic and International Forces and Strategies of Foreign Economic Policy. International Organization, 31 (4), 584-606.

Kimura, E. (2011). Indonesia in 2010. Asian Survery, 51 (1), 186-195.

Landsberg, C. (2010a). Promoting Democracy: The Mandela-Mbeki Doctrine. Journal of Democracy, 11 (3), 107-121.

Landsberg, C. (2010b). South Africa's foreign policy under Thabo Mbeki and Jacob Zuma. Inroads Journal. Disponible en: http://www.inroadsjournal.ca/ transformation-continuity-and-diffusion-south-africas-foreign-policy-underthabo-mbeki-and-jacob-zuma/

Larrabee, S. y Lesser, I. (2003). Turkish Foreign Policy in an Age of Uncertainty. Santa Monica y Pittsburg: RAND Corporation.

Liddle, W. y Mujani, S. (2005). Indonesia in 2004: The Rise of Susilo Bambang Yudhoyono. Asian Survey, 45 (1), 119-126.

MIGA - Multilateral Investment Guarantee Agency. (2012). Disponible en: http:// www.miga.org/documents/WIPR12.pdf

McGrath, L. (1994). Vietnam's struggle to balance sovereignty, centralization, and foreign investment under Doi Moi. Fordham International Law Journal, 18, 2095-2138.

Meyer, K. (2004). Perspectives on Multinational Enterprises in Emerging Economies. Journal of International Business Studies, 35 (4), 259-276.

Ministerio de Relaciones Exteriores (2010). Principios y lineamientos de la política exterior colombiana. Disponible en: http://www.cancilleria.gov.co/ministry/policy

Misión de Política Exterior de Colombia (2010). Informe final, abril de 2010. Disponible en: http://web.presidencia.gov.co/sp/2010/abril/16/mision_politica_exterior.pdf

Mukherjee, B. y Singer, D. (2010). International Institutions and Domestic Compensation: The IMF and the Politics of Capital Account Liberalization. American Journal of Political Science, 54 (1), 45-60. 
Murillo, E. 2012. Hacia una política pública de reconciliación social: tipología y casos. Papel Político, 17 (2), 423-467.

Nas, T. (2008). Tracing the Economic Transformation of Turkey from the 1920 s to EU Accession. The Netherlands: Martinus Nijhoff.

Nathan, L. (2005). Consistency and inconsistencies in South African foreign policy. International Affairs, 81 (2), 361-372.

Nel, P. y Stephen, M. (2010). "The Foreign Economic Policies of Regional Powers in the Developing World”. En: Flemes, D. (Ed.). Regional Leadership in the Global System: Ideas, interests and strategies of regional powers. Farnham-Burlington: Ashgate, pp. 71-90.

Nguen, T. (2007). Investment Climate and Foreign Investment in Vietnam. Studies on Russian Economic Development, 18 (2), 211-218.

Nolte, D. (2010). How to compare regional powers: analytical concepts and research topics. Review of International Studies, 36, 881-901.

Organization of American States. Disponible en: http://www.sice.oas.org/TPD/COL_ EFTA/COL_EFTA_e.ASP

Öniş, Z. (2010). Working Paper Series: Multiple faces of the "new" Turkish foreign policy: underlying dynamics and a critique. Estambul: Center for Globalization and Democratic Governance.

Painter, M. (2005). The politics of state sector reforms in Vietnam: contested agendas and uncertain trajectories. The Journal of Development Studies, 41(2), 261-283.

Pastrana, E. y Vera, D. (2012). "De Uribe a Santos: ¿̇continuidad o nueva orientación de la política exterior colombiana?”. En: Jost, S. (Ed.). Colombia: cuna potencia en desarrollo? Escenarios y desafios para su política exterior. Bogotá: KAS, pp. 57-79.

Ravenhill, J. (2010). “International Political Economy”. En: C. Reus-Smit y D. Snidal (Eds.). The Oxford Handbook of International Relations. Nueva York: Oxford University Press, pp. 539-557.

Salacuse, J. (2010). The Emerging Global Regime for Investment. Harvard Law Review, 51 (2), 427-473.

Shim, D. y Flamm, P. (2012). Rising South Korea: A Minor Player or a Regional Power? GIGA. Disponible en: http://www.giga-hamburg.de/dl/download.php?d=/ content/publikationen/pdf/wp20o_shim-flamm.pdf

Simmons, B. y Zachary, E. (2004). The Globalization of Liberalization: Policy Difussion in the Internatioal Political Economy. The American Political Science Review, 98 (1), 171-189. 
Terzi, Ö. (2010). The Influence of the European Union on Turkish Foreign Policy. Farnham: Ashgate.

Tickner, A. (2007). Intervención por invitación: Claves de la política exterior colombiana y de sus debilidades principales. Colombia Internacional, 65, 90-111.

Togan, S. y Ersel, H. (2005). "Macroeconomic policies for Turkey's accession to the EU”. En: Hoekman, B. y Togan, S. (Eds.). Turkey: Economic Reform and Accession to the European Union. Washington: World Bank Publication, pp. 1-36.

Toh, M. H. y Gayathri, V. (2004). Impact of Regional Trade Liberalization on Emerging Economies. The Case of Vietnam. ASEAN Economic Bulletin, 21 (2), 167-182.

UNCTAD (2004). Key terms and concepts in IIAs: a glossary. UNCTAD Series on Issues in International Investment Agreements. Nueva York-Génova: UN. Disponible en: http://unctad.org/en/Docs/iteiit20042_en.pdf

UNCTAD Database (2013). Disponible en: http://unctad.org/en/Pages/DIAE/International\%2oInvestment\%20Agreements\%2O(IIA)/Country-specific-Lists-of-BITs.aspx

USTR (2013). Disponible en: http://www.ustr.gov/

Vale, P. y Maseko, S. 1998. South Africa and the African Renaissance. International Affairs (Royal Institute of International Affairs 1944), 74 (2), 271-287.

Velosa, E. (2012). "Las ideas y la política exterior colombiana: una mirada desde la teoría del rol nacional y el institucionalismo discursivo”. En: Jost, S. (Ed.). Colombia: ¿una potencia en desarrollo? Escenarios y desafios para su política exterior. Bogotá: KAS, pp. 39-53.

Vuving, A. (2006). Strategy and evolution of Vietnam's China policy: A changing mixtures of pathways. Asian Survery, 46 (6), 805-824.

WTO (2013). Indonesia Trade Policy Review. WT/TPR/S/278.

Zakaria, H. y Baladas, G. (1999). The Political Future of ASEAN after the Asian Crisis. International Affairs, 75 (4), 759-778. 